\title{
Epigenetic and redox biomarkers: Novel insights from the MARK-AGE study
}

\author{
Maria Moreno-Villanueva, Alexander Bürkle* \\ Molecular Toxicology Group, Dept. of Biology, University of Konstanz, D-78457 Konstanz, Germany
}

\begin{tabular}{|c|c|}
\hline & A B S T R A C T \\
\hline $\begin{array}{l}\text { Keywords: } \\
\text { Human ageing } \\
\text { Biomarkers } \\
\text { Chronological age } \\
\text { Biological age } \\
\text { Health span } \\
\text { Observational study } \\
\text { Europe } \\
\text { Nutrition } \\
\text { Peripheral blood mononuclear cells } \\
\text { DNA damage }\end{array}$ & $\begin{array}{l}\text { Ageing is a multifactorial process that affects most, if not all, of the body's tissues and organs and can be defined } \\
\text { as the accumulation of physical and psychological changes in a human being over time. The rate of ageing differs } \\
\text { between individuals of the same chronological age, meaning that 'biological age' of a person may be different } \\
\text { from 'chronological age'. Furthermore, ageing represents a very potent risk factor for diseases and disability in } \\
\text { humans. Therefore, establishment of markers of biological ageing is important for preventing age-associated } \\
\text { diseases and extending health span. MARK-AGE, a large-scale European study, aimed at identifying a set of } \\
\text { biomarkers which, as a combination of parameters with appropriate weighting, would measure biological age } \\
\text { better than any marker in isolation. But beyond the identification of useful biomarkers, MARK-AGE provided } \\
\text { new insights in age-associated specific cellular processes, such as DNA methylation, oxidative stress and the } \\
\text { regulation of zinc homeostasis. }\end{array}$ \\
\hline
\end{tabular}

Oxidative stress

Zinc homeostasis

DNA methyltransferases

Ten-eleven translocation family of 5-mC

hydroxylases

Vaccination

\section{The MARK-AGE study}

The MARK-AGE Consortium consisted of 26 research groups with expertise in the field of ageing research. The study population included about 3200 subjects between 35-74 years of age and was recruited in eight EU countries (Burkle et al., 2015). Standard Operating Procedures for the recruitment of subjects and processing of biological samples (Capri et al., 2015; Moreno-Villanueva et al., 2015a), as well as quality control measures (Jansen et al., 2015) were established at the start of the project.

Anthropometric data as well as clinical and demographic information were collected. Furthermore molecular and biochemical parameters were determined, such as DNA-based markers; markers based on proteins and their modifications; immunological markers; clinical chemistry; hormones and markers of metabolism; markers of oxidative stress; vitamins; and markers based on trace elements. The data obtained was stored in a 'phenotypic database' (Moreno-Villanueva et al., 2015b). While the time period during which the project received financial support has elapsed, data evaluation is ongoing at the time of this writing. The present mini review highlights novel scientific insights that have already been obtained from the MARK-AGE study.

\section{DNA-based biomarkers: genome and epigenome}

\subsection{Epigenetic biomarkers}

Cells are constantly attacked by exogenous and endogenous agents such as reactive oxygen species (ROS), which can damage DNA and disturb epigenetic regulation. The maintenance of the integrity of the genome and epigenome is crucial for optimal cell function. Therefore, cellular protection mechanisms have evolved, e.g. DNA repair systems, for counteracting molecular damage.

There is evidence that the lifespan of a person is positively correlated with cellular DNA repair capacity. For instance, individuals with genetically defective DNA repair have a premature ageing phenotype. Werner syndrome (WS), Bloom syndrome (BLM), Cockayne syndrome (CS), Hutchinson-Gilford progeria syndrome (HGPS), and restrictive dermopathy (RD) are progeria syndromes characterised by high susceptibility to DNA damage due to compromised repair system, either in the repair proteins themselves or in the DNA damage response pathways (Garinis et al., 2008; Musich and Zou, 2009). Furthermore, individuals suffering from other genetic disorders such a Down syndrome (DS) also display premature age-related changes (Esbensen, 2010). DS

\footnotetext{
Corresponding author.

E-mail address: alexander.buerkle@uni-konstanz.de (A. Bürkle).
} 
patients showed lower DNA repair efficiency and also an accelerated decline in DNA repair capacity with age when compared with healthy age-matched individuals, supporting the notion that insufficient DNA repair may be a cause for premature ageing (Raji and Rao, 1998). A more recent publication, however, indicated that although cells from DS patients did display inefficient DNA repair after treatment with hydrogen peroxide, no age or gender-related differences could be detected (Morawiec et al., 2008).

The mechanisms responsible for age-related decline in DNA repair capacity are not fully understood. However, epigenetic changes, including cytosine methylation in DNA might contribute to ageing by dysregulation of DNA repair genes. Recent data indeed showed that methylation of mouse gene encoding oxoguanine glycosylase 1 (Ogg1), which removes the damaged and promutagenic base 8-oxoguanine (8oxoG) from DNA, was significantly increased with ageing and inversely correlated with Ogg1 expression (Langie et al., 2017). There are also molecular mechanisms linking DNA methylation to poly(ADP-ribose) polymerase (PARP). PARP is activated by DNA strand breaks and catalyses the synthesis of a polymeric adenosine diphosphate ribose (poly [ADP-ribose] or PAR) triggering the activation of other DNA repair enzymes such as DNA ligase III (LigIII), DNA polymerase beta (polß), and scaffolding proteins such as X-ray cross-complementing gene 1 (XRCC1) (Isabelle et al., 2010). PARP plays an important role in the regulation of many cellular processes such as DNA repair, cell death, chromatin functions and genomic stability (Burkle and Virág, 2013). Furthermore, poly(ADP-ribosyl)ation has been associated with mammalian longevity (Mangerich and Burkle, 2012). Interestingly, genomewide methylation analyses revealed changes in methylation patterns resulting from inhibition of PARylation in breast cancer cell lines, indicating a reciprocal interplay between PARP1 and DNA methylation (Nalabothula et al., 2015). Caiafa and coworkers demonstrated that inhibition of PARylation induces in vivo DNA hypermethylation (de Capoa et al., 1999; Zardo et al., 1997, 2002) and that CCCTC-binding factor (CTCF) is involved in the cross-talk between poly(ADP-ribosyl) ation and DNA methylation (Guastafierro et al., 2008), suggesting that PAR protects DNA from methylation. The Caiafa group found that PAR, either free or covalently linked with PARP-1 (as an automodification of this enzyme), interacts noncovalently with DNA methyltransferase 1 (DNMT1) and inhibits its enzymatic activity (Caiafa et al., 2009; Reale et al., 2005). DNMT1 transfers a methyl group to the carbon- 5 position of cytosine. This postsynthetic DNA modification is referred to as 5methylcytosine $(5 \mathrm{mC})$ and is considered as the 'fifth base' of the genome. The main function of DNMT1 is to maintain the methylation patterns during replication while the DNMT3A and DNMT3B enzymes mainly introduce methyl groups onto DNA de novo (Jurkowska et al., 2011). In the MARK-AGE Study the variation of DNMT1 and DNMT3B gene expression was assessed in peripheral blood mononuclear cells (PBMCs) from an age-stratified group of more than two thousand women and men (35-75 years) recruited in eight EU countries. The analyses yielded both expected and unexpected results (Ciccarone et al., 2016):

1) A gradually decrease in the expression level of DNMT1 with ageing was observed up to the age of 64 years. Furthermore, DNMT3B expression decreased linearly with increasing age and this association was particularly evident in females.

2) An interaction of the expression of DNMTs with demographic variables was found for gender and BMI, in addition to age and country.

3) Gender differences in the expression of DNMTs in PBMCs are in line with data previously obtained.

4) Surprisingly, dietary habits did not influence the level of DNMTs transcripts although there are indications that DNA methylation is affected by nutrition (Bacalini et al., 2014).

5) There was no association between smoking and level of DNMTs in PBMCs. Cigarette smoking, however, was reported to deregulate the expression of DNMTs in brain (Satta et al., 2008) and lung (Lin et al., 2010) tissues and is thought to be one of the most powerful environmental modifiers of the DNA methylation pattern (Breitling et al., 2011; Lee and Pausova, 2013). The lack of association between DNMTs and cigarette smoking found in MARK-AGE subjects was unexpected.

6) DNMTs expression depended on the PBMC subpopulations. The data suggests that DNMTs might be more highly expressed in lymphocytes than monocytes.

These results confirm, in a large-scale population study, the association between DNMTs expression and ageing.

As mentioned above, DNMTs transfer a methyl group to the carbon5 position of cytosine leads to 5 -methylcytosine $(5 \mathrm{mC})$. However, the $5 \mathrm{mC}$ modification can be oxidized by 5 -mC hydroxylases generating 5 hydroxymethylcytosine $(5 \mathrm{hmC})$. The 'ten-eleven translocation' (TET) family of 5-mC hydroxylases includes TET1, TET2 and TET3. The resulting $5 \mathrm{hmC}$ modification and its derivatives, formylcytosine $(5 \mathrm{fC})$ and carboxylcytosine $(5 \mathrm{caC})$, seem to play a role not only in DNA demethylation but also in transcription and chromatin regulation (Iurlaro et al., 2013) and therefore are now considered "the sixth base" of genome (Song and He, 2011). Recently, a significant age-associated reduction in $5 \mathrm{hmC}$ has been observed in human blood cells, suggesting that DNA hypo-hydroxymethylation can be considered a new biomarker of ageing (Buscarlet et al., 2016). Interestingly, the enzyme thymine DNA glycosylase (TDG) seems to be largely involved in the removal of 5fC and 5caC from DNA (Shen et al., 2013), thus linking 5hydroxymethylcytosine $(5 \mathrm{hmC})$ with DNA repair activities.

In the MARK-AGE study the levels of $5 \mathrm{hmC}, 5 \mathrm{fC}$ and $5 \mathrm{caC}$ as well as TET1, TET2, TET3 and TDG expression were determined, yielding the following results (Valentini et al., 2016):

1) Younger individuals, aged 34-48y, showed significantly higher expression of TET1 and TET3 compared to the 66-74y and the 49-65y age groups, respectively and this effect was independent of the PBMCs subpopulations and gender.

2) $T D G$ expression was slightly negatively correlated with age and this correlation was affected by country of origin.

3) Slight but significant focal DNA hypermethylation events were found in TET1 in the elderly group.

4) Global content of $5 \mathrm{hmC}$ of younger individuals (34-48y) was significantly different from the remaining two groups (49-65y and 66$74 \mathrm{y}$ ). This negative association of $5 \mathrm{hmC}$ with age was influenced by country of origin.

5) An accumulation of $5 \mathrm{caC}$ was observed in older ages while the levels of $5 \mathrm{fC}$ did not change significantly between groups. Furthermore, there was a significant negative association between $5 \mathrm{hmC}$ and $5 \mathrm{caC}$ levels.

6) TET1 gene expression was significantly correlated with $T D G$, DNMT1, DNMT3B, PARP1 and PARP2. A strong correlation was also found between TDG and PARP2.

7) Surprisingly, decision tree analysis identified a positive association between serum alanine aminotransferase (ALT) levels and TET2 expression. This association was not affected by gender, age, lymphocyte/monocyte ratio or country of origin.

The results provide evidence for an age-related decline of TET1, TET3 and TDG gene expression along with a decrease of $5 \mathrm{hmC}$ and an accumulation of $5 \mathrm{caC}$.

Within the MARK-AGE study DS individuals, who are characterized by an acceleration of the ageing process, were also recruited (Capri et al., 2015). The accelerated ageing phenotype of DS has been associated with epigenetic alterations. Using a quantitative molecular marker of ageing known as the 'epigenetic clock', trisomy 21 significantly increases biological age of blood and brain tissue by 4.6 and 11.5 years, respectively (Horvath et al., 2015). The contribution of $5 \mathrm{hmC}$ to the DS pathology so far has been investigated in depth 
(Mendioroz et al., 2015). Results from the MARK-AGE study provide new insights on the role of DNA hydroxymethylation in DS immune cells. Expression of TET genes and $5 \mathrm{hmC}$ levels were analyzed in PBMCs from DS persons and compared with control individuals, yielding the following results (Ciccarone et al., 2017):

1 The levels of $5 \mathrm{hmC}$ were lower in DS samples compared with controls and the difference was independent of the covariates gender, age, and leukocyte composition (lymphocyte/monocyte ratio).

2 Expression levels of TET1 and TET2 were reduced in DS samples with respect to controls. However, the expression of TET2 was affected by confounding factors while TET1 expression was independent of age, gender and lymphocyte/monocyte ratio.

3 TET1 was slightly but significantly hypermethylated in DS PBMC samples.

4 DNMT3A and TDG genes were down-regulated in PBMCs from DS patients and the DNMT3A expression was partially influenced by the leukocyte composition of PBMCs.

5 TET1 and TET3 expression as well as the levels of $5 \mathrm{hmC}$ were significantly lower in DS than in normal young subjects but were not different from the elderly group.

These results support the growing evidence that deregulation of $5 \mathrm{hmC}$ and components of the respective enzymatic machinery can contribute to the ageing process and disease-associated DNA methylation patterns.

\subsection{Oxidative stress biomarkers}

Oxidative stress has been defined as an imbalance between formation and elimination of reactive oxygen species (ROS). ROS comprise oxygen free radicals (e.g. superoxide anion radical; hydroxyl radical) as well as reactive non-radical molecules (e.g. hydrogen peroxide) and are, in part, products of normal cellular metabolism. Physiological levels of ROS determine the cellular redox state and play a role in mediating cell signaling, while pathological levels of ROS can result in oxidative damage (Dai et al., 2014). In 1956, Denham Harman proposed the 'free radical theory of ageing' suggesting that oxygen free radicals / ROS play a central role in the ageing process (Harman, 1956). However, the role of ROS in the biology of ageing might involve more complex cellular processes, including antioxidant systems, that maintain ROS at the physiological levels. In recent years, the balance between ROS production and antioxidant defenses has become a more prominent aspect of the free radical theory of ageing, termed 'redox stress hypothesis', which suggests a pro-oxidizing shift in the redox state of the cells as a primary cause of age-related physiological changes (Sohal and Orr, 2012).

Cellular antioxidant systems include a variety of molecules that can be classified as enzymatic and nonenzymatic scavengers. The major enzymatic antioxidants are superoxide dismutases (SOD), catalase (CAT), and glutathione peroxidases (GPx). Nonenzymatic antioxidants include low-molecular-weight compounds, such as vitamins (vitamins $\mathrm{C}$ and $\mathrm{E}$ ), $\beta$-carotene, uric acid, and glutathione (GSH) (Birben et al., 2012). Several human studies reported age-related changes in cellular antioxidant capacity. For instance, plasma levels of vitamin C, uric acid, vitamin E, vitamin A, carotenoids, total thiol groups, and the activity of plasma SOD and GPx were measured in subjects aged 53-99 years. An age-dependent decrease of the nonenzymatic antioxidants and an agedependent increase of the enzymatic antioxidant activities were observed (Mecocci et al., 2000). A later study on healthy subjects aged 18-80 years reported similar results and showed a significantly higher plasma SOD and CAT activity in older than in younger individuals and suggest that the elevated SOD and CAT activities observed during human ageing might be a compensatory response to the individuals' increased oxidative stress (Rizvi and Maurya, 2007). However, a more recent study found an age-dependent decrease in CAT, SOD, glutathione reductase (GR), GPx and glutathione-S-transferase (GST) enzymatic activity in lymphocytes from healthy individuals aged between 11 and 60 years (Gautam et al., 2010). The apparent discrepancies may be due to dietary habits, season, country, smoking status, or gender and may also be affected by the age range of the studied population. Blood concentrations of micronutrients such as carotenoids and vitamins are, of course, affected by food intake. Although the body possesses several enzymes that scavenge free radicals, micronutrients, such as vitamin $\mathrm{E}$, vitamin $C$, and $\beta$-carotene cannot be synthesized in the body but have to be supplied by the diet. Furthermore, it is known that dietary habits differ strongly between countries.

Within MARK-AGE, plasma samples were collected from healthy subjects aged 35-74 years who have been recruited across EU countries in order to elucidate the role of age, other demographic characteristics, and dietary habits on carotenoids, tocopherols, and retinol (Stuetz et al., 2016). Due to the impact of dietary habits on plasma micronutrients the frequencies of reported intake of fruit, vegetables, and use of vitamin supplements was documented:

1 Intakes of fruit ( $\geq 1$ serving/day) and vegetables ( $\geq 1$ serving/day) were higher in women than in men and in non-smokers compared to smokers.

2 Reported use of vitamin supplements ( $\geq 1$ supplement/week) was also higher in women than in men and in non-smokers compared to smokers.

3 The frequencies of reported use of vitamin supplements ( $\geq 1$ supplement/week) differed significantly between countries.

4 Lycopene and $\alpha$-carotene levels were inversely correlated with age, whereas $\beta$-cryptoxanthin, lutein, zeaxanthin, $\alpha-/ \gamma$-tocopherol, and retinol were positively correlated with age. Cholesterol was positively associated with all carotenoids, tocopherols, and retinol, but was not correlated with age. Cholesterol-adjusted multiple regression analysis confirmed lycopene, $\alpha$-tocopherol, $\alpha$-carotene, and $\beta$ cryptoxanthin to be statistically significant associated with age. The association of lower plasma lycopene with higher age remained after adjusting for co-factors and covariates.

5 Gender, smoking status, BMI, and dietary habits were statistically significantly associated with lycopene, $\alpha$-tocopherol, $\beta$-cryptoxanthin, and $\alpha$-carotene.

6 Lycopene was higher in summer and fall and $\alpha$-tocopherol and $\beta$ cryptoxanthin were higher in winter. Cholesterol was highly and positively associated with $\alpha$-tocopherol.

7 Lower plasma lycopene was associated with overweight and/or obesity, use of vitamin supplements, daily fruit and high frequency in juice consumption, never-consuming French fries and rare but also daily meat servings.

8 Frequent consumption of fruit or vegetables ( $\geq 2$ servings/day) was highly predictive for higher $\beta$-cryptoxanthin and $\alpha$-carotene.

9 The association of higher $\alpha$-tocopherol with age remained after adjusting for country and season, and remained if all covariates were assessed.

10 The inverse association of $\alpha$-carotene with age remained statistically significant even after adjusting for all covariates.

11 Cholesterol, vegetable and fruit consumption, and female gender were positively associated with plasma $\alpha$-carotene in the multiple regression model while the association was a negative one for BMI, smoking, and age group.

Taken together, lycopene, $\alpha$-tocopherol, $\beta$-cryptoxanthin, and $\alpha$ carotene are significantly associated with age even after adjusting for cholesterol, BMI, dietary habits (intake of fruit, vegetables, juice, and meat), use of vitamin supplements, gender, smoking status, country, and season in the age-stratified general population recruited in MARKAGE. But within the MARK-AGE study, subjects were recruited not only from the age-stratified individuals from the general population (RASIG) subgroups, but also subjects belonging to a family with long-living 
members (GO) together with their spouses (SGO) (Capri et al., 2015). Differences between RASIG and the other two groups, with no differences between GO and SGO, could be lifestyle-related while differences between GO and SGO (irrespective of the RASIG results) suggest a genetic contribution. The levels of redox biomarkers, such as protein carbonyls, 3-nitrotyrosine, malondialdehyde, and cellular and plasma antioxidants (glutathione, cysteine, ascorbic acid, uric acid, $\alpha$-tocopherol, and lycopene) were analyzed and compared within the three different subgroups (Weber et al., 2017):

1 After adjustment for age, BMI, smoking status, gender, and country, differences between GO/SGO and the RASIG group were found in protein carbonyls, lycopene, and $\alpha$-tocopherol. Thus, these differences seem to be lifestyle-related.

2 Concentrations of malondialdehyde, 3-nitrotyrosine, and total cysteine were still different between the GO and the RASIG groups even after adjustments, suggesting a genetic contribution.

It was concluded that both lifestyle and genetics might contribute to redox biomarkers in an ageing population.

Metallothioneins (MTs) are zinc-responsive small cysteine-rich proteins involved in metal homeostasis and detoxification. MTs play a role in the redox regulation of $\mathrm{Zn}-\mathrm{S}$ interaction and the coupling of zinc and redox metabolism (Maret, 2004). There is evidence that MT functions as an antioxidant against reactive oxygen and nitrogen species (Ruttkay-Nedecky et al., 2013). Dysregulation of MT seems to affect ageing-related processes and has been associated with longevity (Swindell, 2011). MT transgenic overexpression has been demonstrated to extend mouse life span (Yang et al., 2006). Therefore, MT was selected as a potential biomarker of ageing and was studied in the MARKAGE cohort. Human studies showed age-associated changes in MT protein levels in peripheral blood mononuclear cells (PBMCs) (Malavolta et al., 2008; Mazzatti et al., 2007). In order to elucidate whether these age-related changes are due to altered capability of the cell to induce MT, Zn-induced MT production was assessed in PBMCs from subjects recruited in MARK-AGE (Giacconi et al., 2017):

$1 \mathrm{Zn}$-induced MT is unaffected by age both in lymphocytes and monocytes from the whole population.

2 Zn-induced MT in lymphocytes was significantly higher in RASIG compared to GO and reminded significant after correction for age, gender, and country.

3 Zn-induced MT levels were associated with glycosylated hemoglobin $A_{1 C}$ and fibrinogen serum levels but not with lipid profile (total level of HDL and LDL cholesterol, triglycerides and free fatty acids in serum), serum homocysteine, C-reactive protein, glucose levels, monocyte, and lymphocyte counts.

4 Expression of the Zn transporters genes $M T 1 A$ and $Z n T-1$ was increased in GO as compared to RASIG and SGO and of MT1X in GO compared to RASIG while no differences were observed for $M T 1 H$, MT2A, ZIP2, and ZIP3. MT1E and MT1F isoforms were below the detection limit.

$5 \mathrm{Zn}$-induced MT was inversely correlated with mRNA levels of MT and $\mathrm{Zn}$ transporters genes.

$6 \mathrm{Zn}$-induced MT levels in lymphocytes were negative correlated with 3-nitrotyrosine, malondialdehyde, protein carbonyls in plasma samples and total cysteine in whole blood.

Finally, the MARK-AGE Study already yielded highly relevant and surprising data on the vaccination status of Europeans (Weinberger et al., 2018)

1 Tetanus- and diphtheria-specific antibody concentrations vary greatly between countries, with the frequency of antibody concentrations below the protective level ranging from 2 to $31 \%$ percent for tetanus and $28-63 \%$ for diphtheria.
2 In most countries, tetanus- and diphtheria-specific antibody concentrations decrease with age. This phenomenon is more pronounced in countries with generally low antibody levels, such as Italy, Poland and Greece.

3 Tetanus-specific antibody concentrations are generally higher in males than in females, probably due to systematic vaccination during military service or more frequent booster vaccinations after injuries, whereas no gender-related differences were found for diphtheria-specific antibodies.

4 Viewed together, the European population is universally protected against tetanus and diphtheria.

\section{Summary}

Aging seems to be strongly correlated with changes in the epigenome (Johnson et al., 2012). How methylation may contribute to the ageing process has been discussed and summarized recently (Jung and Pfeifer, 2015). The relationship between DNA methylation and ageing has been described as the epigenetic drift and the epigenetic clock. Epigenetic drift is influenced by environmental factors thus increasing the inter-individual variation with age. In contrast, epigenetic clock sites are common across individuals and highly associated with age, and thus can be used to predict chronological age (Jones et al., 2015; Jung et al., 2017). Epigenetic clocks are sets of CpGs coupled with a mathematical algorithm to estimate the age of cells, tissues or organs and reflect chronological and biological age (Horvath and Raj, 2018). Regarding environmental factors, cigarette smoke is considered a powerful methylation modifier (Breitling et al., 2011). In the MARK-AGE population no association between DNMTs and cigarette smoking could be found. It has been shown that DNA methylation regulator genes can maintain methylation patterns in a tissue-specific and developmentalstage-specific manner (Kang et al., 2017; Rai et al., 2010). Furthermore, methylation levels differ between PBMCs subpopulations in adult subjects (Jacoby et al., 2012), bioinformatic analysis shows complex patterns of inter-individual variation that are strongly correlated with the local DNA sequence (Bock et al., 2008) and results demonstrate a strong genetic component to inter-individual variation in DNA methylation profiles (Bell et al., 2011; Heyn et al., 2013). Interestingly, DNA methylation at three of the strongest maternal-smoking sensitive CpG sites in newborns was influenced by inter-individual genetic variations leading to confounded association between the environmental exposure (maternal smoking) and DNA methylation (Gonseth et al., 2016). All theses variables could explain the lack of association between DNMTs and cigarette smoking found in the MARK-AGE population.

Furthermore, epigenetic inactivation of DNA repair genes has been observed in cancer (Lahtz and Pfeifer, 2011) providing a link between methylation and DNA repair. Here, we have highlighted novel findings from the MARK-AGE study that underpin the evidence of a relationship between two DNA repair enzymes, namely PARP and TDG, and epigenetic changes and how these interactions are associated with ageing processes.

The role of oxidative stress in the development of chronic and degenerative illnesses such as cancer, autoimmune disorders, ageing, cataract, rheumatoid arthritis, cardiovascular and neurodegenerative diseases has been reviewed before (Pham-Huy et al., 2008). Data from the MARK-AGE study support the "redox stress hypothesis". However, both lifestyle and genetics might contribute to the changes in redox biomarkers in an ageing population.

Interestingly, the epigenetic machinery has been proposed as a sensor of oxidative stress involved in the progressive loss of homeostasis associated with the ageing processes (Cencioni et al., 2013). The recent work on the regulation of DNA methylation emanating from the MARKAGE Study, as mentioned above (Ciccarone et al., 2016, 2017; Valentini et al., 2016), reveals new and highly relevant facets, as the data have been obtained in a normal human tissue in vivo.

Likewise, the data presented in the MARK-AGE publications Stuetz 
Table 1

Summary of MARK-AGE findings published as of June 2018

\begin{tabular}{|c|c|}
\hline \multirow[t]{4}{*}{ (Ciccarone et al., 2016) } & Decrease in the expression level of DNMT1 and DNMT3B with age \\
\hline & Interaction of the expression of DNMTs with demographic variables such as gender and BMI, age and country \\
\hline & No association between smoking and level of DNMTs in PBMCs \\
\hline & PBMC subpopulation-dependent expression of DNMTs \\
\hline \multirow[t]{10}{*}{ (Valentini et al., 2016) } & Higher expression of TET1 and TET3 in younger individuals \\
\hline & PBMCs subpopulation-dependent TET1 and TET3 expression \\
\hline & Negative correlation between age and TDG expression affected by country of origin \\
\hline & Focal DNA hypermethylation events found in TET1 in the elderly group \\
\hline & Negative association of $5 \mathrm{hmC}$ with age affected by country of origin \\
\hline & $5 \mathrm{caC}$ accumulation observed in older ages \\
\hline & Negative association between $5 \mathrm{hmC}$ and $5 \mathrm{caC}$ levels \\
\hline & TET1 gene expression correlated with TDG, DNMT1, DNMT3B, PARP1 and PARP2 \\
\hline & Strong correlation between TDG and PARP2 gene expression \\
\hline & TET2 expression positive associated with serum levels of alanine aminotransferase (ALT) \\
\hline \multirow[t]{7}{*}{ (Ciccarone et al., 2017) } & Lower expression of $5 \mathrm{hmC}$ in DS patients independent of gender, age, and leukocyte composition \\
\hline & Lower expression of TET1 and TET2 in DS patients with respect to controls \\
\hline & TET1 expression independent of age, gender and lymphocyte/monocyte ratio \\
\hline & TET1 gene hypermethylated in DS patients \\
\hline & Down regulation of $D N M T 3 A$ and TDG genes in DS patients \\
\hline & DNMT3A expression partially influenced by the leukocyte composition of PBMCs \\
\hline & Lower TET1, TET3 and 5hmC expression in DS patients compared to healthy young subjects but not different from the elderly group \\
\hline \multirow[t]{12}{*}{ (Stuetz et al., 2016) } & Higher fruit, vegetables and vitamin supplements intake in women than in men and in non-smokers compared to smokers \\
\hline & Country differences in the frequencies of reported use of vitamin supplements \\
\hline & Inverse correlation of lycopene and $\alpha$-carotene with age \\
\hline & Positive correlation of $\beta$-cryptoxanthin, lutein, zeaxanthin, $\alpha-/ \gamma$-tocopherol, and retinol with age \\
\hline & Positive association between cholesterol and all carotenoids, tocopherols, and retinol \\
\hline & Association between gender, smoking status, BMI, and dietary habits and lycopene, $\alpha$-tocopherol, $\beta$-cryptoxanthin, and $\alpha$-carotene \\
\hline & Season-dependent variation of lycopene, $\alpha$-tocopherol and $\beta$-cryptoxanthin \\
\hline & Positive association between cholesterol and $\alpha$-tocopherol \\
\hline & Plasma lycopene associated dietary habits \\
\hline & Frequent fruit or vegetable consumption predicts higher $\beta$-cryptoxanthin and $\alpha$-carotene levels \\
\hline & Positive association of cholesterol, vegetable and fruit consumption, and female gender with plasma $\alpha$-carotene \\
\hline & Negative association of cholesterol with BMI, smoking, and age group. \\
\hline \multirow[t]{2}{*}{ (Weber et al., 2017) } & Lifestyle-related differences between GO/SGO and the control group found in protein carbonyls, lycopene, and $\alpha$-tocopherol \\
\hline & $\begin{array}{l}\text { Differences between GO and the RASIG group in concentrations of malondialdehyde, 3-nitrotyrosine and total cysteine even after adjustments, } \\
\text { suggesting a genetic contribution }\end{array}$ \\
\hline \multirow{7}{*}{ (Giacconi et al., 2017) } & No change in Zn-induced MT \\
\hline & Higher Zn-induced MT in lymphocytes from the RASIG population compared to GO \\
\hline & $\begin{array}{l}\text { Negative correlation between Zn-induced MT levels and 3-nitrotyrosine, malondialdehyde, protein carbonyls in plasma and total cysteine in whole } \\
\text { blood. }\end{array}$ \\
\hline & Association between $\mathrm{Zn}$-induced MT levels and glycosylated hemoglobin $\mathrm{A}_{1 \mathrm{C}}$ and fibrinogen in serum \\
\hline & Higher expression of the $\mathrm{Zn}$ transporters genes $M T 1 A$ and $Z n T-1$ in GO as compared to RASIG \\
\hline & Higher expression of $M T 1 X$ in GO compared to RASIG \\
\hline & Inverse correlation between Zn-induced MT and mRNA levels of MT and Zn transporters genes \\
\hline \multirow{3}{*}{ (Weinberger et al., 2018) } & Substantial variation between countries in tetanus- and diphtheria-specific antibody concentrations \\
\hline & $\begin{array}{l}\text { Decrease of tetanus- and diphtheria-specific antibody concentrations with age, especially in countries with generally low antibody levels, such as } \\
\text { Italy, Poland and Greece. }\end{array}$ \\
\hline & $\begin{array}{l}\text { Generally higher tetanus-specific antibody concentrations in males than in females but no gender-related differences for diphtheria-specific } \\
\text { antibodies. }\end{array}$ \\
\hline
\end{tabular}

et al. (2016); Weber et al. (2017) and Giacconi et al. (2017) provide valuable human in vivo results on the intricate crosstalk between nutrition and important nutritional components like vitamins, organic antioxidants, the regulation of zinc homeostasis as well as oxidation markers.

Finally the paper Weinberger et al. (2018) revealed unexpected information on the vaccination status of people living in various European countries. While this work does not primarily address the relation with ageing, the results are highly relevant from a public health point of view.

In conclusion, the MARK-AGE project has already made valuable contributions, both on biomarkers of ageing as such, and also on our mechanistic understanding of human ageing. In Table 1 , the major observations are summarized. We trust that the MARK-AGE project will continue to produce scientific output for the foreseeable future.

\section{Acknowledgements}

We wish to thank the European Commission for financial support of the FP7 large-scale integrating project "European Study to Establish Biomarkers of Human Ageing" (MARK-AGE; grant agreement no.:

\section{0)}

\section{References}

Bacalini, M.G., Friso, S., Olivieri, F., Pirazzini, C., Giuliani, C., Capri, M., Santoro, A., Franceschi, C., Garagnani, P., 2014. Present and future of anti-ageing epigenetic diets. Mech. Ageing Dev. 136-137, 101-115.

Bell, J.T., Pai, A.A., Pickrell, J.K., Gaffney, D.J., Pique-Regi, R., Degner, J.F., Gilad, Y., Pritchard, J.K., 2011. DNA methylation patterns associate with genetic and gene expression variation in HapMap cell lines. Genome Biol. 12, R10.

Birben, E., Sahiner, U.M., Sackesen, C., Erzurum, S., Kalayci, O., 2012. Oxidative stress and antioxidant defense. World Allergy Organ. J. 5, 9-19.

Bock, C., Walter, J., Paulsen, M., Lengauer, T., 2008. Inter-individual variation of DNA methylation and its implications for large-scale epigenome mapping. Nucl. Acids Res. 36, e55.

Breitling, L.P., Yang, R., Korn, B., Burwinkel, B., Brenner, H., 2011. Tobacco-smokingrelated differential DNA methylation: $27 \mathrm{~K}$ discovery and replication. Am. J. Hum. Genet. 88, 450-457.

Burkle, A., Virág, L., 2013. Poly(ADP-ribose): PARadigms and PARadoxes. Mol. Aspects Med . 34, 1046-1065.

Burkle, A., Moreno-Villanueva, M., Bernhard, J., Blasco, M., Zondag, G., Hoeijmakers, J.H., Toussaint, O., Grubeck-Loebenstein, B., Mocchegiani, E., Collino, S., Gonos, E.S., Sikora, E., Gradinaru, D., Dolle, M., Salmon, M., Kristensen, P., Griffiths, H.R., Libert, C., Grune, T., Breusing, N., Simm, A., Franceschi, C., Capri, M., Talbot, D., Caiafa, P., Friguet, B., Slagboom, P.E., Hervonen, A., Hurme, M., Aspinall, R., 2015. MARK-AGE biomarkers of ageing. Mech. Ageing Dev. 151, 2-12. 
Buscarlet, M., Tessier, A., Provost, S., Mollica, L., Busque, L., 2016. Human blood cell levels of 5-hydroxymethylcytosine $(5 \mathrm{hmC})$ decline with age, partly related to acquired mutations in TET2. Exp. Hematol. 44, 1072-1084.

Caiafa, P., Guastafierro, T., Zampieri, M., 2009. Epigenetics: poly(ADP-ribosyl)ation of PARP-1 regulates genomic methylation patterns. FASEB J. 23, 672-678.

Capri, M., Moreno-Villanueva, M., Cevenini, E., Pini, E., Scurti, M., Borelli, V., Palmas, M.G., Zoli, M., Schon, C., Siepelmeyer, A., Bernhardt, J., Fiegl, S., Zondag, G., de Craen, A.J., Hervonen, A., Hurme, M., Sikora, E., Gonos, E.S., Voutetakis, K., Toussaint, O., Debacq-Chainiaux, F., Grubeck-Loebenstein, B., Burkle, A., Franceschi, C., 2015. MARK-AGE population: from the human model to new insights. Mech. Ageing Dev. 151, 13-17.

Cencioni, C., Spallotta, F., Martelli, F., Valente, S., Mai, A., Zeiher, A.M., Gaetano, C., 2013. Oxidative stress and epigenetic regulation in ageing and age-related diseases. Int. J. Mol. Sci. 14, 17643-17663.

Ciccarone, F., Malavolta, M., Calabrese, R., Guastafierro, T., Bacalini, M.G., Reale, A., Franceschi, C., Capri, M., Hervonen, A., Hurme, M., Grubeck-Loebenstein, B., Koller, B., Bernhardt, J., Schn, C., Slagboom, P.E., Toussaint, O., Sikora, E., Gonos, E.S., Breusing, N., Grune, T., Jansen, E., Dolle, M., Moreno-Villanueva, M., Sindlinger, T., Burkle, A., Zampieri, M., Caiafa, P., 2016. Age-dependent expression of DNMT1 and DNMT3B in PBMCs from a large European population enrolled in the MARK-AGE study. Aging Cell 15, 755-765.

Ciccarone, F., Valentini, E., Malavolta, M., Zampieri, M., Bacalini, M.G., Calabrese, R. Guastafierro, T., Reale, A., Franceschi, C., Capri, M., Breusing, N., Grune, T., MorenoVillanueva, M., Burkle, A., Caiafa, P., 2017. DNA hydroxymethylation levels are altered in blood cells from down syndrome persons enrolled in the MARK-AGE project. J. Gerontol. A Biol. Sci. Med. Sci.

Dai, D.F., Chiao, Y.A., Marcinek, D.J., Szeto, H.H., Rabinovitch, P.S., 2014. Mitochondrial oxidative stress in aging and healthspan. Longev. Healthspan 3, 6.

de Capoa, A., Febbo, F.R., Giovannelli, F., Niveleau, A., Zardo, G., Marenzi, S., Caiafa, P., 1999. Reduced levels of poly(ADP-ribosyl)ation result in chromatin compaction and hypermethylation as shown by cell-by-cell computer-assisted quantitative analysis. FASEB J. 13, 89-93.

Esbensen, A.J., 2010. Health conditions associated with aging and end of life of adults with down syndrome. Int. Rev. Res. Ment. Retard. 39, 107-126.

Garinis, G.A., van der Horst, G.T., Vijg, J., Hoeijmakers, J.H., 2008. DNA damage and ageing: new-age ideas for an age-old problem. Nat. Cell Biol. 10, 1241-1247.

Gautam, N., Das, S., Kar Mahapatra, S., Chakraborty, S.P., Kundu, P.K., Roy, S., 2010. Age associated oxidative damage in lymphocytes. Oxid. Med. Cell Longev. 3, 275-282.

Giacconi, R., Costarelli, L., Piacenza, F., Basso, A., Burkle, A., Moreno-Villanueva, M., Grune, T., Weber, D., Stuetz, W., Gonos, E.S., Schon, C., Grubeck-Loebenstein, B., Sikora, E., Toussaint, O., Debacq-Chainiaux, F., Franceschi, C., Hervonen, A., Slagboom, E., Ciccarone, F., Zampieri, M., Caiafa, P., Jansen, E., Dolle, M.E.T., Breusing, N., Mocchegiani, E., Malavolta, M., 2017. Zinc-induced metallothionein in centenarian offspring from a large European population: the MARK-AGE project. J. Gerontol. A Biol. Sci. Med. Sci.

Gonseth, S., de Smith, A.J., Roy, R., Zhou, M., Lee, S.T., Shao, X., Ohja, J., Wrensch, M.R. Walsh, K.M., Metayer, C., Wiemels, J.L., 2016. Genetic contribution to variation in DNA methylation at maternal smoking-sensitive loci in exposed neonates. Epigenetics 11, 664-673.

Guastafierro, T., Cecchinelli, B., Zampieri, M., Reale, A., Riggio, G., Sthandier, O., Zupi, G., Calabrese, L., Caiafa, P., 2008. CCCTC-binding factor activates PARP-1 affecting DNA methylation machinery. J. Biol. Chem. 283, 21873-21880.

Harman, D., 1956. Aging: a theory based on free radical and radiation chemistry. J. Gerontol. 11, 298-300.

Heyn, H., Moran, S., Hernando-Herraez, I., Sayols, S., Gomez, A., Sandoval, J., Monk, D., Hata, K., Marques-Bonet, T., Wang, L., Esteller, M., 2013. DNA methylation contributes to natural human variation. Genome Res. 23, 1363-1372.

Horvath, S., Raj, K., 2018. DNA methylation-based biomarkers and the epigenetic clock theory of ageing. Nat. Rev. Genet. 19, 371-384.

Horvath, S., Garagnani, P., Bacalini, M.G., Pirazzini, C., Salvioli, S., Gentilini, D., Di Blasio, A.M., Giuliani, C., Tung, S., Vinters, H.V., Franceschi, C., 2015. Accelerated epigenetic aging in down syndrome. Aging Cell 14, 491-495.

Isabelle, M., Moreel, X., Gagne, J.P., Rouleau, M., Ethier, C., Gagne, P., Hendzel, M.J., Poirier, G.G., 2010. Investigation of PARP-1, PARP-2, and PARG interactomes by affinity-purification mass spectrometry. Proteome Sci. 8, 22.

Iurlaro, M., Ficz, G., Oxley, D., Raiber, E.A., Bachman, M., Booth, M.J., Andrews, S., Balasubramanian, S., Reik, W., 2013. A screen for hydroxymethylcytosine and formylcytosine binding proteins suggests functions in transcription and chromatin regulation. Genome Biol. 14, R119.

Jacoby, M., Gohrbandt, S., Clausse, V., Brons, N.H., Muller, C.P., 2012. Interindividual variability and co-regulation of DNA methylation differ among blood cell populations. Epigenetics 7, 1421-1434.

Jansen, E., Beekhof, P., Cremers, J., Weinberger, B., Fiegl, S., Toussaint, O., Bernhard, J., Gonos, E., Capri, M., Franceschi, C., Sikora, E., Moreno-Villanueva, M., Breusing, N., Grune, T., Burkle, A., Dolle, M.E., 2015. Quality control data of physiological and immunological biomarkers measured in serum and plasma. Mech. Ageing Dev. 151, 54-59.

Johnson, A.A., Akman, K., Calimport, S.R., Wuttke, D., Stolzing, A., de Magalhaes, J.P., 2012. The role of DNA methylation in aging, rejuvenation, and age-related disease. Rejuvenation Res. 15, 483-494.

Jones, M.J., Goodman, S.J., Kobor, M.S., 2015. DNA methylation and healthy human aging. Aging Cell 14, 924-932

Jung, M., Pfeifer, G.P., 2015. Aging and DNA methylation. BMC Biol. 13, 7.

Jung, S.E., Shin, K.J., Lee, H.Y., 2017. DNA methylation-based age prediction from various tissues and body fluids. BMB Rep. 50, 546-553.

Jurkowska, R.Z., Jurkowski, T.P., Jeltsch, A., 2011. Structure and function of mammalian
DNA methyltransferases. ChemBioChem 12, 206-222.

Kang, S.W., Madkour, M., Kuenzel, W.J., 2017. Tissue-specific expression of DNA methyltransferases involved in early-life nutritional stress of chicken, gallus gallus. Front. Genet. 8, 204.

Lahtz, C., Pfeifer, G.P., 2011. Epigenetic changes of DNA repair genes in cancer. J. Mol. Cell Biol. 3, 51-58.

Langie, S.A., Cameron, K.M., Ficz, G., Oxley, D., Tomaszewski, B., Gorniak, J.P., Maas, L.M., Godschalk, R.W., van Schooten, F.J., Reik, W., von Zglinicki, T., Mathers, J.C., 2017. The ageing brain: effects on DNA repair and DNA methylation in mice. Genes (Basel) 8.

Lee, K.W., Pausova, Z., 2013. Cigarette smoking and DNA methylation. Front. Genet. 4, 132.

Lin, R.K., Hsieh, Y.S., Lin, P., Hsu, H.S., Chen, C.Y., Tang, Y.A., Lee, C.F., Wang, Y.C., 2010. The tobacco-specific carcinogen NNK induces DNA methyltransferase 1 accumulation and tumor suppressor gene hypermethylation in mice and lung cancer patients. J. Clin. Invest. 120, 521-532.

Malavolta, M., Cipriano, C., Costarelli, L., Giacconi, R., Tesei, S., Muti, E., Piacenza, F., Pierpaoli, S., Larbi, A., Pawelec, G., Dedoussis, G., Herbein, G., Monti, D., Jajte, J., Rink, L., Mocchegiani, E., 2008. Metallothionein downregulation in very old age: a phenomenon associated with cellular senescence? Rejuvenation Res. 11, 455-459.

Mangerich, A., Burkle, A., 2012. Pleiotropic cellular functions of PARP1 in longevity and aging: genome maintenance meets inflammation. Oxid. Med. Cell Longev. 2012, 321653.

Maret, W., 2004. Zinc and sulfur: a critical biological partnership. Biochemistry 43, 3301-3309.

Mazzatti, D.J., Malavolta, M., White, A.J., Costarelli, L., Giacconi, R., Muti, E., Cipriano, C., Powell, J.R., Mocchegiani, E., 2007. Differential effects of in vitro zinc treatment on gene expression in peripheral blood mononuclear cells derived from young and elderly individuals. Rejuvenation Res. 10, 603-620.

Mecocci, P., Polidori, M.C., Troiano, L., Cherubini, A., Cecchetti, R., Pini, G., Straatman, M., Monti, D., Stahl, W., Sies, H., Franceschi, C., Senin, U., 2000. Plasma antioxidants and longevity: a study on healthy centenarians. Free Radic. Biol. Med. 28, $1243-1248$.

Mendioroz, M., Do, C., Jiang, X., Liu, C., Darbary, H.K., Lang, C.F., Lin, J., Thomas, A., Abu-Amero, S., Stanier, P., Temkin, A., Yale, A., Liu, M.M., Li, Y., Salas, M., Kerkel, K., Capone, G., Silverman, W., Yu, Y.E., Moore, G., Wegiel, J., Tycko, B., 2015. Trans effects of chromosome aneuploidies on DNA methylation patterns in human down syndrome and mouse models. Genome Biol. 16, 263.

Morawiec, Z., Janik, K., Kowalski, M., Stetkiewicz, T., Szaflik, J., Morawiec-Bajda, A., Sobczuk, A., Blasiak, J., 2008. DNA damage and repair in children with down's syndrome. Mutat Res. 637, 118-123.

Moreno-Villanueva, M., Capri, M., Breusing, N., Siepelmeyer, A., Sevini, F., Ghezzo, A., de Craen, A.J., Hervonen, A., Hurme, M., Schon, C., Grune, T., Franceschi, C., Burkle, A., 2015a. MARK-AGE standard operating procedures (SOPs): a successful effort. Mech. Ageing Dev. 151, 18-25.

Moreno-Villanueva, M., Kotter, T., Sindlinger, T., Baur, J., Oehlke, S., Burkle, A., Berthold, M.R., 2015b. The MARK-AGE phenotypic database: structure and strategy. Mech. Ageing Dev. 151, 26-30.

Musich, P.R., Zou, Y., 2009. Genomic instability and DNA damage responses in progeria arising from defective maturation of prelamin a. Aging (Albany, NY) 1, 28-37.

Nalabothula, N., Al-jumaily, T., Eteleeb, A.M., Flight, R.M., Xiaorong, S., Moseley, H., Rouchka, E.C., Fondufe-Mittendorf, Y.N., 2015. Genome-wide profiling of PARP1 reveals an interplay with Gene regulatory regions and DNA methylation. PLoS One 10, e0135410.

Pham-Huy, L.A., He, H., Pham-Huy, C., 2008. Free radicals, antioxidants in disease and health. Int. J. Biomed. Sci. 4, 89-96.

Rai, K., Jafri, I.F., Chidester, S., James, S.R., Karpf, A.R., Cairns, B.R., Jones, D.A., 2010. Dnmt3 and G9a cooperate for tissue-specific development in zebrafish. J. Biol. Chem. 285, 4110-4121.

Raji, N.S., Rao, K.S., 1998. Trisomy 21 and accelerated aging: DNA-repair parameters in peripheral lymphocytes of Down's syndrome patients. Mech. Ageing Dev. 100, 85-101.

Reale, A., Matteis, G.D., Galleazzi, G., Zampieri, M., Caiafa, P., 2005. Modulation of DNMT1 activity by ADP-ribose polymers. Oncogene 24, 13-19.

Rizvi, S.I., Maurya, P.K., 2007. Alterations in antioxidant enzymes during aging in humans. Mol. Biotechnol. 37, 58-61.

Ruttkay-Nedecky, B., Nejdl, L., Gumulec, J., Zitka, O., Masarik, M., Eckschlager, T., Stiborova, M., Adam, V., Kizek, R., 2013. The role of metallothionein in oxidative stress. Int. J. Mol. Sci. 14, 6044-6066.

Satta, R., Maloku, E., Zhubi, A., Pibiri, F., Hajos, M., Costa, E., Guidotti, A., 2008. Nicotine decreases DNA methyltransferase 1 expression and glutamic acid decarboxylase 67 promoter methylation in GABAergic interneurons. Proc. Natl. Acad. Sci. U. S. A. 105, $16356-16361$.

Shen, L., Wu, H., Diep, D., Yamaguchi, S., D’Alessio, A.C., Fung, H.L., Zhang, K., Zhang, Y., 2013. Genome-wide analysis reveals TET- and TDG-dependent 5-methylcytosine oxidation dynamics. Cell 153, 692-706.

Sohal, R.S., Orr, W.C., 2012. The redox stress hypothesis of aging. Free Radic. Biol. Med. 52, 539-555.

Song, C.X., He, C., 2011. The hunt for 5-hydroxymethylcytosine: the sixth base. Epigenomics 3, 521-523.

Stuetz, W., Weber, D., Dolle, M.E., Jansen, E., Grubeck-Loebenstein, B., Fiegl, S., Toussaint, O., Bernhardt, J., Gonos, E.S., Franceschi, C., Sikora, E., MorenoVillanueva, M., Breusing, N., Grune, T., Burkle, A., 2016. Plasma carotenoids, tocopherols, and retinol in the age-stratified (35-74 years) General population: a crosssectional study in six European countries. Nutrients 8.

Swindell, W.R., 2011. Metallothionein and the biology of aging. Ageing Res. Rev. 10, 
$132-145$.

Valentini, E., Zampieri, M., Malavolta, M., Bacalini, M.G., Calabrese, R., Guastafierro, T., Reale, A., Franceschi, C., Hervonen, A., Koller, B., Bernhardt, J., Slagboom, P.E.,

Toussaint, O., Sikora, E., Gonos, E.S., Breusing, N., Grune, T., Jansen, E., Dolle, M.E., Moreno-Villanueva, M., Sindlinger, T., Burkle, A., Ciccarone, F., Caiafa, P., 2016. Analysis of the machinery and intermediates of the 5hmC-mediated DNA demethylation pathway in aging on samples from the MARK-AGE study. Aging (Albany, NY) 8, 1896-1922.

Weber, D., Stuetz, W., Toussaint, O., Debacq-Chainiaux, F., Dolle, M.E.T., Jansen, E., Gonos, E.S., Franceschi, C., Sikora, E., Hervonen, A., Breusing, N., Sindlinger, T., Moreno-Villanueva, M., Burkle, A., Grune, T., 2017. Associations between specific redox biomarkers and age in a large European cohort: the MARK-Age project. Oxid. Med. Cell Longev. 2017, 1401452.

Weinberger, B., Keller, M., Putzer, C., Breitenberger, D., Koller, B., Fiegl, S., Moreno-
Villanueva, M., Bernhardt, J., Franceschi, C., Voutetakis, K., Gonos, E.S., Hurme, M., Sikora, E., Toussaint, O., Debacq-Chainiaux, F., Grune, T., Breusing, N., Burkle, A., Grubeck-Loebenstein, B., 2018. Protection against tetanus and diphtheria in Europe: the impact of age, gender and country of origin based on data from the MARK-AGE study. Exp. Gerontol. 105, 109-112.

Yang, X., Doser, T.A., Fang, C.X., Nunn, J.M., Janardhanan, R., Zhu, M., Sreejayan, N., Quinn, M.T., Ren, J., 2006. Metallothionein prolongs survival and antagonizes senescence-associated cardiomyocyte diastolic dysfunction: role of oxidative stress. FASEB J. 20, 1024-1026.

Zardo, G., D’Erme, M., Reale, A., Strom, R., Perilli, M., Caiafa, P., 1997. Does poly(ADPribosyl)ation regulate the DNA methylation pattern? Biochemistry 36, 7937-7943.

Zardo, G., Reale, A., Passananti, C., Pradhan, S., Buontempo, S., De Matteis, G., Adams, R.L., Caiafa, P., 2002. Inhibition of poly(ADP-ribosyl)ation induces DNA hypermethylation: a possible molecular mechanism. FASEB J. 16, 1319-1321. 